\title{
Near-infrared spectroscopy for monitoring leg perfusion during minimally invasive surgery for patients with congenital heart defects
}

\author{
Vladimiro L. Vida, MD, PhD, ${ }^{\mathrm{a}}$ Massimo A. Padalino, MD, PhD, ${ }^{\mathrm{a}}$ Giovanna Boccuzzo, MPH, ${ }^{\mathrm{b}}$ and \\ Giovanni Stellin, MD, ${ }^{\mathrm{a}}$ Padua, Italy
}

Regional oxygen saturation measured by means of nearinfrared spectroscopy (NIRS) have been used as potential surrogate of cerebral and somatic mixed venous oxygen saturation and has been suggested as a noninvasive tool to continuously monitor and detect states of low body perfusion. $^{1-5}$ We sought to evaluate the safety of peripheral arterial cannulation by using NIRS in patients undergoing minimally invasive heart surgery for correcting simple congenital heart diseases, focusing on patients with a body weight less than $30 \mathrm{~kg}$.

\section{PATIENTS}

We evaluated 50 patients who underwent remote cardiopulmonary bypass (CPB) by femoral cannulation for the correction of simple congenital heart defects between January 2009 and May 2011. ${ }^{1,2}$ The distal femoral artery had not been occluded in our patients and a distal selective arterial perfusion was not used.

NIRS (using the INVOS 5100 cerebral oximeter; Somanetics Corp, Troy, Mich) was used to continuously monitor any variation of oxygen saturation during the extracorporeal perfusion on both lower extremities (NIRS sensors are positioned on the anterior side). After the operation, creatine kinase (CK) and myoglobin plasmatic levels were evalu-

From the Pediatric and Congenital Cardiac Surgery Unit, ${ }^{a}$ Department of Cardiac, Thoracic and Vascular Surgery, and the Department of Statistical Science, ${ }^{\mathrm{b}}$ University of Padua, Padua, Italy.

Disclosures: Authors have nothing to disclose with regard to commercial support.

Received for publication Sept 27, 2011; revisions received Oct 21, 2011; accepted for publication Nov 7, 2011; available ahead of print Dec 6, 2011.

Address for reprints: Vladimiro L. Vida, MD, PhD, Pediatric and Congenital Cardiac Surgery Unit, Department of Cardiac, Thoracic and Vascular Surgery, University of Padua, Via Giustiniani, 2-35128, Padua, Italy (E-mail: vladimirovida@yahoo.it). J Thorac Cardiovasc Surg 2012;143:756-7

$0022-5223 / \$ 36.00$

Copyright (c) 2012 by The American Association for Thoracic Surgery

doi:10.1016/j.jtcvs.2011.11.005 ated, together with the CPB time and the type of surgical approach.

Median age at surgery was 17.9 years (range, 6-56 years) and median body weight was $48 \mathrm{~kg}$ (range, 18-91 kg). Primary surgical maneuvers included (1) ostium secundum atrial septal closure $(n=40),(2)$ repair of partial anomalous pulmonary venous return $(n=8)$, and (3) discrete subaortic membrane resection $(n=2)$. The surgical approach was through a right anterior minithoracotomy in 35 patients, a right posterior minithoracotomy in 13 , and a ministernotomy in 2. Femoral vessels were cannulated through a pursestring suture in all. During CPB, at full flows, median NIRS values dropped from 81 (range, 72-88) to 50.5 (range, $20-71 ; P=.001)$ in the cannulated leg whereas it remained stable on the contralateral leg; this was found related to the body weight of the patients (Table 1). No patient required conversion to central cannulation or the additional cannulation of the contralateral leg for flow reasons, and we did not need to reconstruct the femoral vessels after decannulation. We did not record any sign of perioperative leg ischemia at the end of surgery, and postoperative vascular ultrasound revealed a normal perfusion of the cannulated extremity without evidence of stenosis in all. Peak median postoperative CK levels were $680 \mathrm{U} / \mathrm{L}$ (range, 291-28,736 U/L), 2 (4\%) patients having a level greater than $4000 \mathrm{U} / \mathrm{L}$. The peak median postoperative plasmatic myoglobin level was $380 \mathrm{U} / \mathrm{L}$ (range, 84-6430 U/L), with 4 (8\%) patients having a level greater than $1000 \mathrm{U} / \mathrm{L}$ (Tables 1 and 2). A forward linear regression analysis correlates the increase of plasmatic $\mathrm{CK}$ and myoglobin level to CPB time $(P<.0001)$. There were no clinical side effects from the increased $\mathrm{CK}$ of myoglobin. It is of note that different surgical approaches required different perfusion times, which were longer in patients who required a posterior right minithoracotomy (Table 2). On that basis, we determined that a remote CPB time longer than 80 minutes would explain

TABLE 1. Somatic NIRS values on the cannulated leg and perfusion data according to patient's body weight $(\mathrm{n}=50$ patients)

\begin{tabular}{|c|c|c|c|c|}
\hline & $\begin{array}{c}\text { BW 18-30 kg } \\
(n=11)\end{array}$ & $\begin{array}{c}\text { BW 31-50 kg } \\
(n=16)\end{array}$ & $\begin{array}{c}\text { BW }>51 \mathrm{~kg} \\
(\mathrm{n}=23)\end{array}$ & $P *$ \\
\hline Median NIRS value before cannulation (range) & $81(76-88)$ & $81.5(78-87)$ & $79(72-88)$ & .1 \\
\hline Median NIRS value during CPBP (range) & $34(20-47)$ & $43.5(32-67)$ & $55(45-71)$ & $<.001$ \\
\hline Median NIRS value after decannulation (range) & $83(74-86)$ & $80.5(75-86)$ & $77(72-86)$ & .1 \\
\hline Median CPB time (range) & $45(21-228)$ & $41.5(23-170)$ & $58(31-160)$ & .7 \\
\hline Peak CK plasmatic level in U/L (range) & $682(413-28,736)$ & $1263(446-7,072)$ & $666(291-2,110)$ & .4 \\
\hline Peak myoglobin plasmatic level in mg/dL (range) & $368(84-6,430)$ & $722(480-1,899)$ & $254(87-977)$ & .7 \\
\hline
\end{tabular}

NIRS, Near-infrared spectroscopy; $B W$, body weight; $C P B$, cardiopulmonary bypass; $C K$, creatine kinase. *Kruskal-Wallis test. 
TABLE 2. Somatic NIRS values on the cannulated leg and perfusion data according to the type of surgical approach $(n=50$ patients)

\begin{tabular}{lccc}
\hline & $\begin{array}{c}\text { Ministernotomy } \\
(\mathbf{n}=\mathbf{2})\end{array}$ & $\begin{array}{c}\text { Anterior right MT } \\
(\mathbf{n}=\mathbf{3 5})\end{array}$ & $\begin{array}{c}\text { Posterior right MT } \\
(\mathbf{n}=\mathbf{1 3})\end{array}$ \\
\hline Median NIRS value during CPB (range) & $45(34-56)$ & $50(20-71)$ & $51(34-67)$ \\
Median body weight (range) & $34(26-42)$ & $47(18-81)$ & .7 \\
Median CPB time (range) & $53(45-62)$ & $41(21-141)$ & .3 \\
Peak CK plasmatic level in U/l (range) & $555(480-630)$ & $556(291-1,444)$ & $108(73-228)$ \\
Peak myoglobin plasmatic level in mg/dl (range) & $341(270-412)$ & $368(84-621)$ & $2046(975-28,736)$ \\
\hline
\end{tabular}

NIRS, Near-infrared spectroscopy; $M T$, minithoracotomy; $C P B$, cardiopulmonary bypass; $C K$, creatine kinase. *Kruskal-Wallis test.

a significant increase of both $\mathrm{CK}$ and myoglobin plasmatic levels in patients with a body weight of less than $30 \mathrm{~kg}$ where the NIRS values on the cannulated leg reach levels more than 30 .

\section{DISCUSSION}

A prolonged period of limb ischemia in patients undergoing minimally invasive operations, especially when the femoral artery has been clamp occluded, has the potential to cause ischemic complications. ${ }^{3}$ The use of NIRS to monitor the lower extremities in these patients was a valid and reproducible method for assessing tissue oxygenation of the perfused leg, immediately showing signs of leg ischemia if insufficient leg perfusion is provided. ${ }^{4,5}$

According to our results, there was a significant drop of the tissue oxygenation (as decreased NIRS values) after femoral artery cannulation and CPB, which was found in direct correlation with the body weight of the patient. We did not have any case of peripheral leg ischemia; however, we found increased postoperative levels of CK and myoglobin levels that were directly correlated to the time of distal leg perfusion. On the contrary, no association was found between the CK and myoglobin level and the NIRS values during CPB or patient's body weight.
We speculate that the remote $\mathrm{CPB}$ with direct femoral artery cannulation can be safely used in patients with a body weight less than $30 \mathrm{~kg}$ without increased operative morbidity or complications. The prolonged CPB time is associated with plasmatic elevation of $\mathrm{CK}$ and myoglobin levels, especially in patients with a low body weight $(<30 \mathrm{~kg})$ and with very low NIRS values $(<30)$ on the cannulated leg during extracorporeal perfusion. Inasmuch as different surgical approaches required different $\mathrm{CPB}$ times and consequently a longer distal leg perfusion time (ie, right posterior minithoracotomy), we intend to change our minimally invasive policy by adding selective distal leg perfusion when prolonged CPB time is expected.

\section{References}

1. Vida VL, Padalino MA, Boccuzzo G, Veshti AA, Speggiorin S, Falasco G, et al Minimally invasive operation for congenital heart disease: a sex-differentiated approach. J Thorac Cardiovasc Surg. 2009;138:933-6.

2. Vida VL, Padalino MA, Motta R, Stellin G. Minimally invasive surgical options in pediatric heart surgery. Expert Rev Cardiovasc Ther. 2011;9:763-9.

3. Bonaros N, Wiedemann D, Nagiller J, Feuchtner G, Kolbitsch C, Kaufmann M, et al. Distal leg protection for peripheral cannulation in minimally invasive and totally endoscopic cardiac surgery. Heart Surg Forum. 2009;12:E158-62.

4. Schachner T, Bonaros N, Bonatti J, Kolbitsch C. Near infrared spectroscopy for controlling the quality of distal leg perfusion in remote access cardiopulmonary bypass. Eur J Cardiothorac Surg. 2008;34:1253-4.

5. Schachner T, Bonaros N, Feuchtner G, Müller L, Laufer G, Bonatti J. How to handle remote access perfusion for endoscopic cardiac surgery. Heart Surg Forum. 2005;8:E232-5 